\title{
Sonidegib, a novel smoothened inhibitor for the treatment of advanced basal cell carcinoma
}

This article was published in the following Dove Press journal:

OncoTargets and Therapy

14 September 2016

Number of times this article has been viewed

\author{
Hung Q Doan' \\ Sirunya Silapunt' \\ Michael R Migden ${ }^{2,3}$ \\ 'Department of Dermatology, \\ University of Texas, McGovern \\ Medical School, ${ }^{2}$ Mohs Surgery \\ Unit, Department of Dermatology, \\ ${ }^{3}$ Department of Head and Neck \\ Surgery, The University of Texas MD \\ Anderson Cancer Center, Houston, \\ TX, USA
}

\begin{abstract}
Basal cell carcinoma (BCC) is the most common nonmelanoma skin cancer. If left untreated, BCCs can become locally aggressive or even metastasize. Currently available treatments include local destruction, surgery, and radiation. Systemic options for advanced disease are limited. The Hedgehog $(\mathrm{Hh})$ pathway is aberrantly activated in a majority of BCCs and in other cancers. Hh pathway inhibitors are targeted agents that inhibit the aberrant activation of the Hh pathway, with smoothened being a targeted component. Sonidegib is a novel smoothened inhibitor that was recently approved by the US Food and Drug Administration. This review focuses on $\mathrm{BCC}$ pathogenesis and the clinical efficacy of sonidegib for the treatment of advanced BCC.
\end{abstract}

Keywords: nonmelanoma skin cancer, Hedgehog pathway, clinical trials

\section{Introduction}

Basal cell carcinoma (BCC) is the most common nonmelanoma skin cancer. ${ }^{1}$ BCCs can occur sporadically or in familial genetic syndromes where patients harbor a mutation in key regulatory genes. When left untreated, BCCs can become locally aggressive and may metastasize, limiting the efficacy of standard treatment. Much attention has been given to targeted Hedgehog pathway inhibition (HPI) as a means to treat advanced BCC: locally advanced lesions that are deemed inappropriate for surgery or radiation or metastatic lesions. To date, only two Hedgehog (Hh) pathway inhibitor agents have been approved by the US Food and Drug Administration (FDA): vismodegib and sonidegib. The purpose of this review is to provide a broad introduction to the molecular mechanisms underlying BCC pathogenesis and the role of sonidegib, a targeted smoothened inhibitor, in modulating the natural history of advanced BCC.

\section{Clinical features of BCCs}

Approximately 750,000 BCCs are detected each year, and BCC is the fifth most costly cancer among Medicare patients. ${ }^{2,3}$ BCC often appears with characteristic features of a slow growing papule that often heals slowly after a minor trauma, although many clinical variants exist. With time, they can ulcerate and continue to grow without detection by the patient. BCCs tend to occur more often in men than in women and more frequently in patients aged $>50$ years. These tumors are typically associated with a history of increased sun exposure, although it is uncertain whether extensive sun exposure or intermittent cumulative sun exposure is most associated with this cancer. ${ }^{4}$

BCCs also occur in genetically susceptible individuals. Patients with basal cell nevus syndrome (BCNS or Gorlin syndrome) have a propensity early in life to spontaneously develop multiple BCCs. Additionally, these patients have other clinical features including
Correspondence: Michael R Migden Mohs Surgery Unit, Department of Dermatology, The University of Texas MD Anderson Cancer Center, I5I 5 Holcombe Boulevard, Unite I452, Houston, TX 77030, USA

Tel + I 7135631665

Fax +I 7137453597

Email mrmigden@mdanderson.org 
palmar pitting, odontogenic cysts, calcification of the falx cerebri, midline craniofacial abnormalities, and an increased risk in some other neoplasms, including medulloblastomas, rhabdomyosarcomas, meningiomas, and ovarian fibromas. ${ }^{5}$ Given the larger number of developing lesions, these patients often receive multiple treatment modalities for their BCCs.

Most BCCs are effectively treated with local destruction or surgical management such as Mohs micrographic surgery or wide local excision. Less commonly, small lesions may be treated with cryotherapy, electrodessication and curettage, or topical agents, including 5-fluoruracil cream or the immunomodulator imiquimod.

While BCC is the most common and easily treated skin cancer, metastases are rare. Risk factors associated with locally advanced or metastatic disease include clinical size $>2.5 \mathrm{~cm}$, high-risk anatomic location (central portion of the face or ears), long-standing duration, incomplete excision, aggressive histology, and perineural or perivascular involvement. ${ }^{6}$ Metastases occur most commonly when the primary tumor occurs on the face, with metastases first to the regional lymph nodes, followed by bone, lung, or liver. ${ }^{6}$ Systemic chemotherapy and radiation have been employed to treat metastatic BCC (metBCC) with very limited success. ${ }^{7-10}$ Additionally, advanced BCC can be disfiguring and emotionally distressing to patients, which can limit their perception of receiving adequate care during therapy. With the advent of targeted smoothened inhibitors, patients now have more treatment options available to them.

\section{The molecular basis of BCC pathogenesis}

The pathogenesis of BCC has been elucidated including identification of aberrant Hh pathway signaling and associated mutations in the Patched $(P T C H)$ and smoothened (SMO) genes. ${ }^{11}$ Hahn et al ${ }^{12}$ demonstrated that BCNS patients harbored a germline mutation in the $P T C H$ gene. $P T C H$ was subsequently mapped to chromosome 9q22.3 and is homologous to the Drosophila patched gene, which mediates midline development. ${ }^{13}$ Furthermore, $>50 \%-60 \%$ of spontaneous cutaneous BCCs possess PTCH mutations. ${ }^{14}$ Given these findings, it was proposed that $\mathrm{BCC}$ is a disease of aberrant $\mathrm{Hh}$ pathway signaling. ${ }^{14} \mathrm{PTCH}$, as originally described, is now designated as PTCH1. PTCH2, a closely related homolog, located on chromosome $1 \mathrm{p} 32$, has been discovered and is mutated in some cases of BCNS and meduloblastomas. ${ }^{15}$

\section{Hh signaling pathway}

Hh signaling is an evolutionarily conserved pathway that is necessary in embryonic development mediating organogenesis and midline development. Given its importance in development, this pathway is tightly regulated-alterations of which have been found in many cancers. The Hh ligands are sonic Hh (Shh), Indian Hh (Ihh), and desert Hh (Dhh). Other major components of the pathway include PTCH1/2, smoothened, and GLI. In the absence of the Hh ligand, PTCH1/2 is constitutively bound to and inhibits the intracellular protein smoothened. In canonical Hh signaling, the Hh ligand binds to and inhibits PTCH1/2, in turn freeing smoothened to activate downstream GLI transcription factors (Figure 1). ${ }^{16,17}$ Consequently, abnormal activation of this pathway promotes tumorigenesis and is etiologic in a majority of sporadic and familial BCCs. Loss-of-function mutations in PTCH1 or PTCH2 or activating mutations in $S M O$ are seen in at least $70 \%$ of sporadic BCCs. ${ }^{18-20}$ This mode of Hh pathway activation is referred to as mutationdependent activation.

Conversely, other cancer types including pancreatic, lung, and breast have demonstrated a ligand-dependent mode of aberrant Hh signaling where either tumor or stromal cells secrete Hh ligand. ${ }^{21-25}$ Given the relevance of this pathway in many solid cancers, specific HPI could potentially modulate tumor progression in a wide variety of cancer types.

\section{Hh pathway inhibition}

In 1965, scientists at the Poisonous Plant Research Laboratory of the US Department of Agriculture reported that pregnant ewes grazing on the corn lily, Veratrum californicum, produced cyclopic sheep. ${ }^{26}$ The toxin causing the cyclopic defect was isolated from $V$. californicum and named cyclopamine. ${ }^{27,28}$ Subsequently, two separate groups established that cyclopamine inhibits the Hh signaling pathway. ${ }^{29,30}$ Cyclopamine possesses anticancer activity in cell culture and animal studies; however, cyclopamine has limited bioavailability due to low water solubility and instability under acidic conditions, which may limit its clinical utility. ${ }^{31-35}$ Cyclopamine derivatives have been developed to circumvent these limitations and the cyclopamine derivative IPI-926 has demonstrated some clinical activity in BCC patients in a Phase I dose-finding study. ${ }^{36-38}$ Clinical and preclinical studies have also investigated other HPIs including GANT58, GANT61, HPI1-4, and robotnikinin, which inhibit other components of the Hh pathway. ${ }^{39-41}$ Itraconazole, an antifungal agent, has also shown some clinical activity against advanced BCC alone and in combination with arsenic trioxide. ${ }^{42,43}$

To date, two HPIs have been approved by the FDA: vismodegib and sonidegib. These currently available HPIs specifically function by inhibition of Smo, thus inhibiting aberrant Smo activation found in a majority of BCCs. 


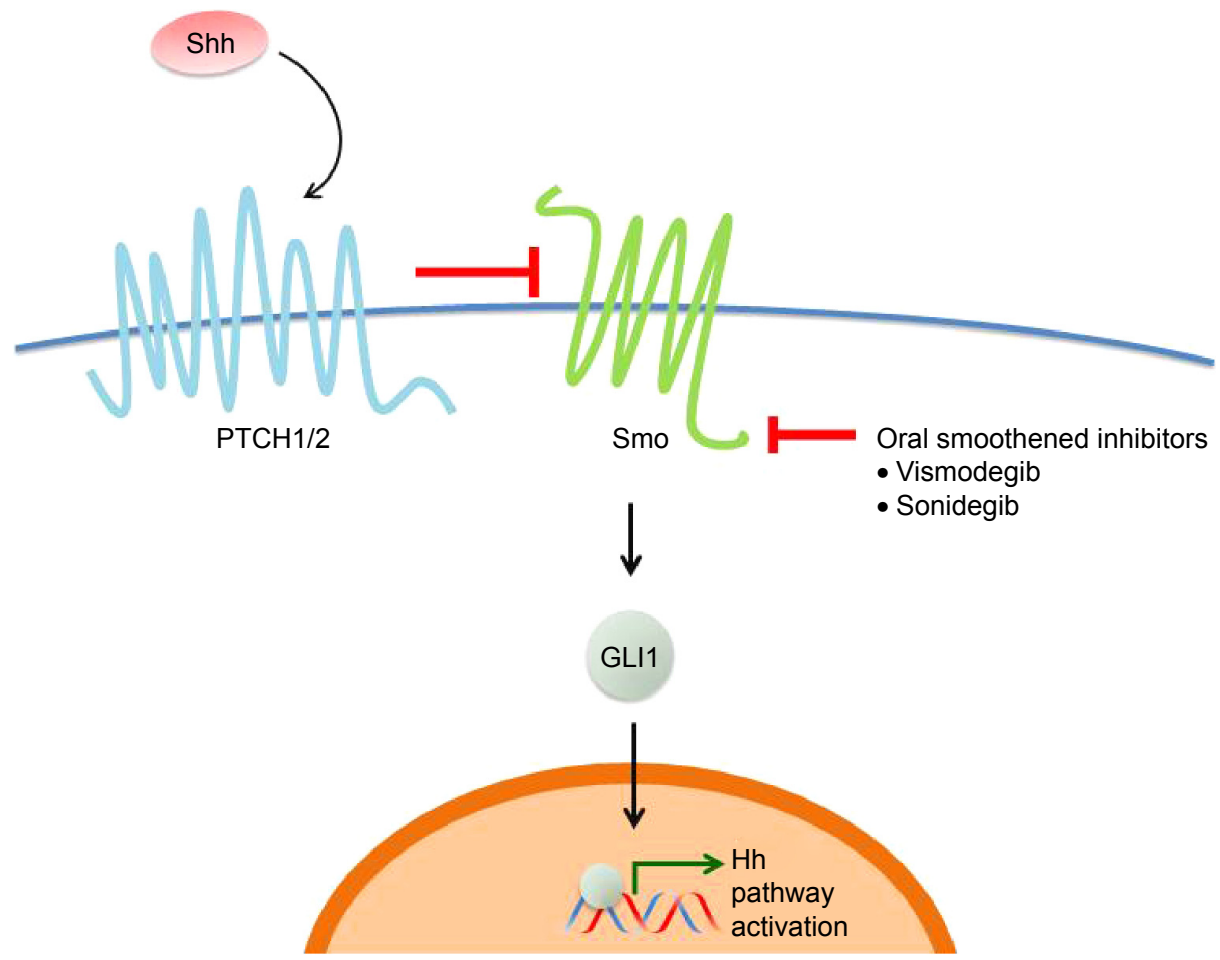

Figure I Hedgehog ( $\mathrm{Hh}$ ) pathway. PTCHI/2 (patched) constitutively inhibits smoothened (Smo).

Notes: Inhibition of PTCHI, either through Hh ligand binding or inactivating mutations in PTCHI, promotes Smo activation. Smo activation, in turn, leads to GLII transcriptional activation and upregulation of Smo-dependent genes. Oral smoothened inhibitors inhibit Smo activation, leading to a downregulation of GLII-dependent transcriptional activity.

Abbreviation: Shh, sonic Hh.

Clinical trials currently underway are investigating the clinical benefits of HPI in various human cancers (Table 1).

Regarding the treatment of advanced BCC, sonidegib (Odomzo ${ }^{\circledR}$; Novartis International AG, Basel, Switzerland) is a novel Smo antagonist that is approved in the US and European Union for locally advanced BCC (laBCC) that has recurred following surgery or radiation therapy or for patients who are not candidates for surgery or radiation therapy. In Switzerland and Australia, sonidegib is approved for adult patients with locally advanced and metBCC. ${ }^{44}$

Sonidegib was first identified in 2010 as compound LDE225 while screening biphenyl carboxamides that displayed potent HPI and antitumor activity in a medulloblastoma allograft model. ${ }^{45}$ In this study, sonidegib possessed Smo

Table I Smoothened inhibitors currently in development

\begin{tabular}{lll}
\hline Drug & Manufacturer & Trials \\
\hline BMS-833923 & $\begin{array}{l}\text { Bristol-Myers } \\
\text { Squibb }\end{array}$ & CML (NCT0I2 I8477) \\
$\begin{array}{l}\text { Glasdegib } \\
\text { (PF-044499|3) }\end{array}$ & $\begin{array}{l}\text { Pfizer } \\
\text { LEQ506 }\end{array}$ & MDS (NCT0I842646) \\
LDE255 & Novartis & $\begin{array}{l}\text { Solid tumors, medulloblastoma, } \\
\text { and aBCC (NCT0I I06508) }\end{array}$ \\
\hline
\end{tabular}

Abbreviations: CML, chronic myelogenous leukemia; MDS, myelodysplastic syndrome; aBCC, advanced basal cell carcinoma. inhibition with high tissue penetration, good oral bioavailability, and the ability to cross the blood-brain barrier.

\section{Early clinical studies of sonidegib}

A subsequent open-label, dose-escalated Phase I trial of sonidegib in advanced solid tumors demonstrated activity against medulloblastoma and advanced BCC. ${ }^{46}$ This study investigated doses ranging from $100 \mathrm{mg}$ to $3,000 \mathrm{mg}$ once daily and from $250 \mathrm{mg}$ to $750 \mathrm{mg}$ twice daily. The maximum tolerated dose was $800 \mathrm{mg}$ daily and $250 \mathrm{mg}$ twice daily. Common Grade 1/2 adverse effects (AEs) noted in this study include nausea, dysgeusia (abnormal sensation of taste), anorexia, vomiting, myalgias, muscle spasms, fatigue, alopecia, and increased serum creatine kinase (CK). Grade 3/4 AEs included weight loss, myalgia, hyperbilirubinemia, dizziness, and fatigue. Of note, reversible Grade 3/4 CK elevation was considered dose limiting in 19 patients (18\%) at doses exceeding the maximum tolerated dose and was reported to occur 3-6 weeks after initiating the drug in an exposure-dependent manner. In most cases, the CK elevation was associated with myalgia. Importantly, six of 16 BCC patients in this trial (37.5\%) achieved an objective tumor response (defined as partial or complete response, CR) according to RECIST criteria and fluorodeoxyglucose positron emission tomography imaging studies. 
A topical preparation of sonidegib was also investigated for the treatment of sporadic superficial and nodular BCC. Although there was initial enthusiasm about the potential for this topical preparation, a Phase II trial was terminated early due to insufficient efficacy using the formulation evaluated. ${ }^{47}$ Another topical HPI tested in the Phase I setting, CUR61414, did not demonstrate clinical efficacy, which may have been due to inadequate drug concentrations, low penetration, or rapid clearance. ${ }^{48}$

A recent trial demonstrated little clinical efficacy of sonidegib in BCC patients whose disease was stable or progressed on vismodegib. In this trial, nine patients were enrolled although four patients discontinued. Of the five evaluable patients, three had metastatic disease that is notoriously difficult to treat with any modality. Of the two locally advanced patients, one had a treatment duration of only 3 weeks, and the other patient had a treatment duration of 6 weeks, which may preclude adequate evaluation of sonidegib efficacy. Given these limitations, the study authors suggest that patients whose BCCs are resistant to vismodegib may progress on another Smo inhibitor. Since both vismodegib and sonidegib inhibit smoothened within the binding pocket, there is potential to develop novel therapies at other sites of smoothened or to inhibit other components of the $\mathrm{Hh}$ pathway. ${ }^{49}$ Buonamici demonstrated in a mouse xenograft model of medulloblastoma that was resistant to sonidegib that concomitant inhibition of Hh pathway and the IGF-R/ $\mathrm{PI} 3 \mathrm{~K} / \mathrm{Akt}$ pathway may overcome resistance to sonidegib. This mechanism is not yet fully understood and provides potential avenues for further drug targets. ${ }^{50}$

While no head-to-head trials exist in comparing sonidegib with vismodegib, another FDA-approved HPI, it is interesting to note that both drugs have unique dose responses. In a Phase I trial of vismodegib, there were no observed dose-related responses - plasma concentration of vismodegib remained relatively constant despite escalating doses. This observation is thought to be due to high plasma protein binding. ${ }^{51,52}$ In a Phase I study, sonidegib demonstrated a dose-related response rate based on pharmacokinetic and molecular studies although it is unclear if this is due to altered plasma protein binding. ${ }^{46}$ Because of these differing dose responses, one might hypothesize that patients may experience a more sustained response once steady state is achieved with sonidegib.

\section{Basal cell carcinoma outcomes trial}

The pivotal Phase II study demonstrating clinical benefit with sonidegib for the treatment of BCCs was the Basal cell carcinoma Outcomes in LDE225 Treatment (BOLT) trial. This study was an international randomized, doubleblind Phase II trial evaluating two doses of sonidegib in
230 patients with metBCC or laBCC not amenable to local therapy. Patients were randomized in a 2:1 ratio and were treated with either $800 \mathrm{mg}(\mathrm{n}=151)$ or $200 \mathrm{mg}(\mathrm{n}=79)$ until disease progression or unacceptable toxicity. Other patient characteristics are summarized in Table 2. The $200 \mathrm{mg}$ dose previously showed exposure in the predictive range with acceptable antitumor activity and the $800 \mathrm{mg}$ dose was the highest well-tolerated dose in a once-daily regimen. Tumor response was assessed by a central review committee and by study investigators using two methods: RECIST Version 1.1 criteria for patients with metBCC, which is based on MRI assessment and by modified RECIST (mRECIST) to assess patients with laBCC. ${ }^{53}$ mRECIST is a stringent composite multimodal evaluation, which integrates MRI data according to RECIST 1.1, standard and annotated color photography according to WHO criteria, and histology in multiple biopsies based on lesion surface area. mRECIST is a more thorough method used to assess locally advanced disease in the setting of potential ulceration, cyst formation, scarring, fibrosis, and ill-defined lesion borders that may occur with treatment. Using the stringent mRECIST criteria, in order to qualify as a $\mathrm{CR}$, a CR (or equivalent) must be demonstrated in all modalities: MRI, bidimensional measurements from standard and annotated photography, and all multiple surveying biopsies being reported as negative.

The primary end point of BOLT was the objective response rate (ORR) determined by central review in patients with laBCC and metBCC. Key secondary end points in the study were duration of response (DoR) and CR rate determined by central review. Other secondary end points were ORR and DoR as determined by investigator review, the time to tumor response, duration of progression-free survival (PFS) as determined by central and investigator review, and safety. Objective response (OR) encompassed

Table 2 BOLT trial overview

\begin{tabular}{lll}
\hline Patient characteristics & $\mathbf{2 0 0} \mathbf{~} \mathbf{g}(\mathbf{n}=\mathbf{7 9})$ & $\mathbf{8 0 0} \mathbf{~ m g ~ ( n = 1 5 ~ I ) ~}$ \\
\hline $\begin{array}{l}\text { Age, years } \\
\text { Sex, } \mathrm{n}(\%)\end{array}$ & $67(23-92)$ & $65(24-93)$ \\
Female & $31(39)$ & $55(36)$ \\
$\quad$ Male & $48(6 \mathrm{I})$ & $96(64)$ \\
Metastases, n (\%) & $14(18)$ & $23(15)$ \\
Lung & $10(7 \mathrm{I})$ & $12(52)$ \\
Lymph nodes & $1(7)$ & $7(30)$ \\
Bone & $2(14)$ & $5(22)$ \\
Other & $3(2 \mathrm{I})$ & $7(30)$ \\
\hline
\end{tabular}

Note: Adapted from The Lancet, Vol 16 edition (6) Migden, MR, Guminski A, Gutzmer, et al. Treatment with two different doses of sonidegib in patients with locally advanced or metastatic basal cell carcinoma (BOLT): a multicentre, randomised, double-blind phase 2 trial. Pages No., 716-728, Copyright (2015), with permission from Elsevier..$^{55}$

Abbreviation: BOLT, Basal cell carcinoma Outcomes in LDE225 Treatment. 
both $\mathrm{CR}$ and partial response (PR). Complete response for this study was defined as complete disappearance of all lesions and all negative surveying biopsies obtained from two or more sites as assessed by a single independent review panel. PR was defined as achieving at least a 50\% reduction in the sum of products of perpendicular diameters of locally advanced target lesions based on photography and at least a $30 \%$ reduction in the sum of longest diameters of all target lesions assessable by MRI. Response of metastatic disease was based on standard RECIST 1.1 criteria. The median duration of treatment was 8.9 months in the $200 \mathrm{mg}$ dose group and 6.5 months in the $800 \mathrm{mg}$ dose group.

The primary efficacy analysis demonstrated an OR in 20 of $55(36 \%, 95 \%$ CI $24-50)$ patients in the $200 \mathrm{mg}$ dose group and 39 of $116(34 \%, 25-43)$ patients in the $800 \mathrm{mg}$ group meeting the study's success criteria of accomplishing an ORR $\geq 30 \%$ in both treatment arms (laBCC and metBCC combined; Table 3). By central review, two patients with laBCC (3\%) experienced a CR with $200 \mathrm{mg}$ sonidegib; by investigator review, five patients experienced a $\mathrm{CR}$ with $200 \mathrm{mg}$ sonidegib. In the laBCC treatment group, 76 patients achieved an OR, only seven (four in the $200 \mathrm{mg}$ group and three in the $800 \mathrm{mg}$ group) had disease progression or died before primary analysis cutoff. Durable responses lasting $>6$ months in patients with laBCC were seen in 12 of 31 (39\%) patients in the $200 \mathrm{mg}$ group and 17 of $45(38 \%)$ of patients in the $800 \mathrm{mg}$ group. Median PFS in the laBCC patients was not reached in either dose group as measured by central review. Median PFS by investigator review was reported to be 22 months with the $200 \mathrm{mg}$ sonidegib dose but not reached with the $800 \mathrm{mg}$ dose. The DoR by central review was not reached in either dosing; the DoR by investigator review was 20.2 months with the $200 \mathrm{mg}$ dose but not reached with the $800 \mathrm{mg}$ dose.
ORs lasting at least 6 months at the time of primary efficacy cutoff were seen in five of six patients with metBCC. No substantial differences in OR were found when comparing different subgroups stratified based on histology or geographical location. By central review, no patients with metBCC experienced a CR; by investigator review, two patients $(9 \%)$ had a CR with $800 \mathrm{mg}$ of sonidegib. In metBCC patients, the median PFS was 13.1 months in the $200 \mathrm{mg}$ sonidegib dose group and 7.6 months in the $800 \mathrm{mg}$ dose group by central review; the median PFS values were 13.1 months and 13.3 months by investigator review.

The most common AEs noted were muscle spasms, dysgeusia, alopecia, nausea, increased CK, weight decrease, and fatigue. These AEs were less frequent in the $200 \mathrm{mg}$ sonidegib than in the $800 \mathrm{mg}$ sonidegib group. Consequently, fewer AE-related dose interruptions, reductions, or treatment discontinuations were seen in the $200 \mathrm{mg}$ group than in the $800 \mathrm{mg}$ group. Serious AEs were reported in $14 \%$ of patients in the $200 \mathrm{mg}$ sonidegib group and $30 \%$ in the $800 \mathrm{mg}$ sonidegib group. Secondary malignancies were noted in $6 \%(200 \mathrm{mg})$ and $7 \%(800 \mathrm{mg})$ of patients. Four patients in the $800 \mathrm{mg}$ group died while taking study treatment, but none of these deaths was deemed to be related to sonidegib. Owing to improved tolerability and similar efficacy between these two doses, it was concluded that the $200 \mathrm{mg}$ sonidegib dosing offered a more favorable benefit-to-risk profile.

This study employed a PCR-based assessment of GLI1 expression as a marker of Hh pathway activation. The change in GLI1 expression was assessed from tumor biopsy samples obtained at the time of screening, at weeks 9, 17, and at the end of treatment. As expected, a sustained reduction in GLI1 expression was seen in patients with disease control $(\mathrm{CR}+$ $\mathrm{PR}+$ stable disease) confirming HPI.

Table 3 Objective responses to sonidegib in BOLT

\begin{tabular}{|c|c|c|c|c|c|c|c|c|}
\hline & \multicolumn{4}{|c|}{ Primary efficacy analysis } & \multicolumn{4}{|c|}{ Intention to treat } \\
\hline & \multicolumn{2}{|l|}{$200 \mathrm{mg}$} & \multicolumn{2}{|l|}{$800 \mathrm{mg}$} & \multicolumn{2}{|l|}{$200 \mathrm{mg}$} & \multicolumn{2}{|l|}{$800 \mathrm{mg}$} \\
\hline & $\begin{array}{l}\text { laBCC, } \\
n=42\end{array}$ & $\begin{array}{l}\text { metBCC, } \\
n=13\end{array}$ & $\begin{array}{l}\text { laBCC, } \\
n=93\end{array}$ & $\begin{array}{l}\text { metBCC, } \\
n=23\end{array}$ & $\begin{array}{l}\text { laBCC, } \\
n=66\end{array}$ & $\begin{array}{l}\text { metBCC, } \\
n=13\end{array}$ & $\begin{array}{l}\text { laBCC, } \\
n=\mid 28\end{array}$ & $\begin{array}{l}\text { metBCC, } \\
n=13\end{array}$ \\
\hline Proportion of patients with OR (central review) & 18 & 2 & 35 & 4 & 31 & 2 & 45 & 4 \\
\hline Complete response & 2 & 0 & 0 & 0 & 2 & 0 & 0 & 0 \\
\hline Partial response & 16 & 2 & 35 & 4 & 29 & 2 & 45 & 4 \\
\hline Disease control & 39 & 12 & 74 & 19 & 60 & 12 & 100 & 19 \\
\hline Proportion of patients with OR (investigator) & 28 & 3 & 54 & 8 & 43 & 3 & 73 & 8 \\
\hline Complete response & 3 & 0 & 12 & 2 & 5 & 0 & 15 & 2 \\
\hline Partial response & 25 & 3 & 42 & 6 & 38 & 3 & 58 & 6 \\
\hline Disease control & 39 & II & 82 & 19 & 59 & II & 110 & 19 \\
\hline
\end{tabular}

Note: Adapted from The Lancet, Vol 16 edition (6) Migden, MR, Guminski A, Gutzmer, et al. Treatment with two different doses of sonidegib in patients with locally advanced or metastatic basal cell carcinoma (BOLT): a multicentre, randomised, double-blind phase 2 trial. Pages No., 7I6-728, Copyright (20I5), with permission from Elsevier. ${ }^{55}$

Abbreviations: BOLT, Basal cell carcinoma Outcomes in LDE225 Treatment; laBCC, locally advanced BCC; metBCC, metastatic basal cell carcinoma; OR, objective response. 
The BOLT study also assessed the impact on patientreported quality of life (QOL) because advanced BCC can lead to emotional or psychological stress, in turn impacting a patient's QOL. Two questionnaires based on the European Organization for Research and Treatment of Cancer were employed: the Quality of Life Questionnaire C30 (QLQ-C30) typically employed in oncology and the associated module for head and neck cancers, the H\&N35. Prespecified relevantto-advanced BCC subscales were selected from these QOL questionnaires. These included physical functioning, social functioning, pain, and fatigue for QLQ-C30, and trouble with social contact, head and neck pain, and weight loss for H\&N35. These QOL data were collected up to 6 months after randomization of the last patient with a median follow-up of 13.9 months. In patients with laBCC, most responders had maintenance of or improvement in scores on both QLQ-C30 and H\&N35 in both sonidegib dose arms. Similar QOL results were noted in metBCC as most patients had maintenance of or improvement in scores from baseline on both questionnaires. The BOLT study demonstrated a clear role of Smo inhibitors in the treatment of advanced BCC and a favorable benefit-to-risk profile was noted for most patients.

\section{I2-month follow-up of the BOLT trial}

The original BOLT study reported the results of the primary analysis with data collected up to 6 months after randomization of the last patient, with a median follow-up of 13.9 months. Efficacy and safety data 12 months following randomization of the last patient have also been presented. ${ }^{54}$ At the time of primary analysis, a total of 144 patients $(63 \%)$ had discontinued the treatment primarily due to AEs and an additional 35 patients $(77.8 \%)$ had discontinued the treatment in the 12-month follow-up.

The 12-month analysis demonstrated a higher ORR in both the $200 \mathrm{mg}$ and the $800 \mathrm{mg}$ arms, up to $11 \%$ (58\% vs $47 \%$ ) and $9 \%$ (44\% vs 35\%), respectively, for laBCC. Furthermore, 48 of $51(92.3 \%)$ patients in the $200 \mathrm{mg}$ arm and 91 of 101 (90.1\%) patients in the $800 \mathrm{mg}$ arm (91/101) demonstrated laBCC tumor shrinkage as analyzed by photography per WHO criteria, demonstrating a clear clinical benefit. Of the responders, $52.6 \%$ treated with $200 \mathrm{mg}$ sonidegib and $53.6 \%$ treated with $800 \mathrm{mg}$ sonidegib demonstrated a durable antitumor response of $>6$ months among 94 patients with laBCC, 18 patients (19.1\%) had disease progression or died. Median PFS by central review was 22.1 months with the $200 \mathrm{mg}$ dose group and 21.5 months with the $800 \mathrm{mg}$ dose group; the respective median PFS by investigator review was 22.0 months and 21.5 months. The median DoR by central review was not reached with $200 \mathrm{mg}$ because few responders progressed or died and was 15.7 months with the $800 \mathrm{mg}$; median DoR values by investigator review were 20.2 months and 19.8 months. A CR was observed in $4.5 \%$ of laBCC patients with $200 \mathrm{mg}$ and $1.6 \%$ with $800 \mathrm{mg}$ by central review; by investigator review, a CR was observed in $9.1 \%$ and $10.9 \%$ of patients, respectively. Efficacy of the metBCC subgroups in the 12-month analysis was similar to that in the primary analysis. The ORR by central review was $7.7 \%$ and $17.4 \%$ in the $200 \mathrm{mg}$ and $800 \mathrm{mg}$ arms, respectively. Tumor shrinkage was noted in $84.6 \%$ of patients treated with sonidegib $200 \mathrm{mg}$ and $81.8 \%$ of patients treated with sonidegib $800 \mathrm{mg}$. Additionally, $92.3 \%$ and $91.3 \%$ in the $200 \mathrm{mg}$ and $800 \mathrm{mg}$ arms, respectively, experienced DC. Median PFS in metBCC patients was 13.1 months in the $200 \mathrm{mg}$ and 11.1 months in the $800 \mathrm{mg}$ by central review; respective PFS values as measured by investigator review for metBCC were 13.1 months and 14.3 months. Median DoR for metBCC was not reached as measured by central review at either dose; median DoR by investigator review was 17.7 months with the $200 \mathrm{mg}$ and 10.2 months with the $800 \mathrm{mg}$. As measured by central review, no metBCC patients experienced a $\mathrm{CR}$; by investigator review $8.7 \%$ of patients experienced a CR with $800 \mathrm{mg}$ sonidegib.

The safety profile of sonidegib in the 12-month follow-up data was similar to the primary analysis data. As with the primary analysis, the most common AEs were muscle spasms, alopecia, dysgeusia, nausea, increased $\mathrm{CK}$, and fatigue being the most common adverse events among the subjects. Approximately $97.5 \%$ of those in the $200 \mathrm{mg}$ sonidegib group and $100 \%$ of those in the $800 \mathrm{mg}$ sonidegib group experienced an AE. These events led $27.8 \%$ and $37.3 \%$ of patients in the $200 \mathrm{mg}$ and $800 \mathrm{mg}$ arms, respectively, to discontinue study medication. The 12-month follow-up data also showed that $91.1 \%$ of the sonidegib $200 \mathrm{mg}$ patients and $70.0 \%$ of the sonidegib $800 \mathrm{mg}$ patients remained on treatment for at least 4 months.

At the time of the 12-month analysis, three additional deaths occurred since the primary analysis and none were associated with treatment-related AEs. A low percentage of patients $(1.3 \%$ in the $200 \mathrm{mg}$ sonidegib and $3.3 \%$ in the $800 \mathrm{mg}$ sonidegib group) were reported to have had a CK elevation (at least a tenfold from baseline). These findings, however, were not confirmed by the independent safety review and adjudication committee on muscle toxicity as rhabdomyolysis (defined as a tenfold increase in CK above baseline plus a serum creatinine elevation of at least 1.5 -fold above baseline) owing to normal renal function.

\section{Conclusion}

Patients with advanced BCC have limited options and the condition is considered difficult to treat at best. As our 
understanding of the molecular mechanisms underlying BCC improves, targeted therapies will continue to play an important role in the treatment of advanced BCC. The BOLT trial demonstrated that sonidegib had a durable clinical benefit for patients whose disease was not controlled or amenable to treatment through surgery or radiation. QOL for these patients is an important consideration and QOL measures assessed by BOLT indicated that most patients experienced stable or improved QOL. The 12-month analysis of safety and efficacy confirmed the antitumor effect seen in the primary analysis with similar safety data. BOLT study investigators suggest that future therapeutic options may include sonidegib in combination with other treatment modalities to accomplish tumor control. Further studies would be needed to investigate which options are best for patients with advanced BCC.

\section{Disclosure}

Michael R Migden has received honoraria for serving on the advisory boards of Genentech, Novartis Pharmaceuticals, and Eli Lilly. The authors report no other conflicts of interest in this work.

\section{References}

1. Rogers HW, Weinstock MA, Harris AR, et al. Incidence estimate of nonmelanoma skin cancer in the United States, 2006. Arch Dermatol. 2010;146(3):283-287.

2. Miller DL, Weinstock MA. Nonmelanoma skin cancer in the United States: incidence. J Am Acad Dermatol. 1994;30(5 pt 1):774-778.

3. Housman TS, Feldman SR, Williford PM, et al. Skin cancer is among the most costly of all cancers to treat for the Medicare population. $\mathrm{J} \mathrm{Am}$ Acad Dermatol. 2003;48(3):425-429.

4. Kricker A, Armstrong BK, English DR, Heenan PJ. A dose-response curve for sun exposure and basal cell carcinoma. Int J Cancer. 1995; 60(4):482-488.

5. John AM, Schwartz RA. Basal cell naevus syndrome: an update on genetics and treatment. Br J Dermatol. 2016;174(1):68-76.

6. Walling HW, Fosko SW, Geraminejad PA, Whitaker DC, Arpey CJ. Aggressive basal cell carcinoma: presentation, pathogenesis, and management. Cancer Metastasis Rev. 2004;23(3-4):389-402.

7. Guthrie TH Jr, Porubsky ES, Luxenberg MN, Shah KJ, Wurtz KL, Watson PR. Cisplatin-based chemotherapy in advanced basal and squamous cell carcinomas of the skin: results in 28 patients including 13 patients receiving multimodality therapy. J Clin Oncol. 1990;8(2):342-346.

8. Moeholt K, Aagaard H, Pfeiffer P, Hansen O. Platinum-based cytotoxic therapy in basal cell carcinoma - a review of the literature. Acta Oncol. 1996;35(6):677-682.

9. Rowe DE, Carroll RJ, Day CL Jr. Long-term recurrence rates in previously untreated (primary) basal cell carcinoma: implications for patient follow-up. J Dermatol Surg Oncol. 1989;15(3):315-328.

10. Hulyalkar R, Rakkhit T, Garcia-Zuazaga J. The role of radiation therapy in the management of skin cancers. Dermatol Clin. 2011;29(2): 287-296.

11. Epstein EH. Basal cell carcinomas: attack of the hedgehog. Nat Rev Cancer. 2008;8(10):743-754.

12. Hahn H, Wicking C, Zaphiropoulous PG, et al. Mutations of the human homolog of Drosophila patched in the nevoid basal cell carcinoma syndrome. Cell. 1996;85(6):841-851.

13. Johnson RL, Rothman AL, Xie J, et al. Human homolog of patched, a candidate gene for the basal cell nevus syndrome. Science. 1996;272(5268):1668-1671.
14. Gailani MR, Stahle-Backdahl M, Leffell DJ, et al. The role of the human homologue of Drosophila patched in sporadic basal cell carcinomas. Nat Genet. 1996;14(1):78-81.

15. Smyth I, Narang MA, Evans T, et al. Isolation and characterization of human patched 2 ( $\mathrm{PTCH} 2$ ), a putative tumour suppressor gene inbasal cell carcinoma and medulloblastoma on chromosome 1p32. Hum Mol Genet. 1999;8(2):291-297.

16. Hui CC, Angers S. Gli proteins in development and disease. Annu Rev Cell Dev Biol. 2011;27:513-537.

17. Briscoe J, Therond PP. The mechanisms of Hedgehog signalling and its roles in development and disease. Nat Rev Mol Cell Biol. 2013;14(7): 416-429.

18. Aszterbaum M, Rothman A, Johnson RL, et al. Identification of mutations in the human PATCHED gene in sporadic basal cell carcinomas and in patients with the basal cell nevus syndrome. J Invest Dermatol. 1998;110(6):885-888.

19. Reifenberger J, Wolter M, Knobbe CB, et al. Somatic mutations in the PTCH, SMOH, SUFUH and TP53 genes in sporadic basal cell carcinomas. Br J Dermatol. 2005;152(1):43-51.

20. Xie J, Murone M, Luoh SM, et al. Activating smoothened mutations in sporadic basal-cell carcinoma. Nature. 1998;391(6662):90-92.

21. O'Toole SA, Machalek DA, Shearer RF, et al. Hedgehog overexpression is associated with stromal interactions and predicts for poor outcome in breast cancer. Cancer Res. 2011;71(11):4002-4014.

22. Watkins DN, Berman DM, Burkholder SG, Wang B, Beachy PA, Baylin SB. Hedgehog signalling within airway epithelial progenitors and in small-cell lung cancer. Nature. 2003;422(6929):313-317.

23. Bailey JM, Mohr AM, Hollingsworth MA. Sonic hedgehog paracrine signaling regulates metastasis and lymphangiogenesis in pancreatic cancer. Oncogene. 2009;28(40):3513-3525.

24. Yauch RL, Gould SE, Scales SJ, et al. A paracrine requirement for hedgehog signalling in cancer. Nature. 2008;455(7211):406-410.

25. Tian H, Callahan CA, DuPree KJ, et al. Hedgehog signaling is restricted to the stromal compartment during pancreatic carcinogenesis. Proc Natl Acad Sci US A. 2009;106(11):4254-4259.

26. Binns W, Shupe JL, Keeler RF, James LF. Chronologic evaluation of teratogenicity in sheep fed Veratrum californicum.J Am Vet Med Assoc. 1965;147(8):839-842.

27. Keeler RF, Binns W. Teratogenic compounds of Veratrum californicum (Durand). V. Comparison of cyclopian effects of steroidal alkaloids from the plant and structurally related compounds from other sources. Teratology. 1968;1(1):5-10.

28. Keeler RF. Teratogenic compounds of Veratrum californicum (Durand). VII. The structure of the glycosidic alkaloid cycloposine. Steroids. 1969;13(5):579-588.

29. Cooper MK, Porter JA, Young KE, Beachy PA. Teratogen-mediated inhibition of target tissue response to Shh signaling. Science. 1998; 280(5369):1603-1607.

30. Incardona JP, Gaffield W, Kapur RP, Roelink H. The teratogenic Veratrum alkaloid cyclopamine inhibits sonic hedgehog signal transduction. Development. 1998;125(18):3553-3562.

31. Keeler RF. Cyclopamine and related steroidal alkaloid teratogens: their occurrence, structural relationship, and biologic effects. Lipids. 1978;13(10):708-715.

32. Taipale J, Chen JK, Cooper MK, et al. Effects of oncogenic mutations in smoothened and patched can be reversed by cyclopamine. Nature. 2000;406(6799):1005-1009.

33. Koike C, Mizutani T, Ito T, et al. Introduction of wild-type patched gene suppresses the oncogenic potential of human squamous cell carcinoma cell lines including A431. Oncogene. 2002;21(17):2670-2678.

34. Berman DM, Karhadkar SS, Hallahan AR, et al. Medulloblastoma growth inhibition by hedgehog pathway blockade. Science. 2002;297(5586): $1559-1561$.

35. Low JA, de Sauvage FJ. Clinical experience with Hedgehog pathway inhibitors. J Clin Oncol. 2010;28(36):5321-5326.

36. Tremblay MR, Nevalainen M, Nair SJ, et al. Semisynthetic cyclopamine analogues as potent and orally bioavailable hedgehog pathway antagonists. J Med Chem. 2008;51(21):6646-6649. 
37. Kumar SK, Roy I, Anchoori RK, et al. Targeted inhibition of hedgehog signaling by cyclopamine prodrugs for advanced prostate cancer. Bioorg Med Chem. 2008;16(6):2764-2768.

38. Jimeno A, Weiss GJ, Miller WH Jr, et al. Phase I study of the Hedgehog pathway inhibitor IPI-926 in adult patients with solid tumors. Clin Cancer Res. 2013;19(10):2766-2774.

39. Lauth M, Bergstrom A, Shimokawa T, Toftgard R. Inhibition of GLI-mediated transcription and tumor cell growth by small-molecule antagonists. Proc Natl Acad Sci U S A. 2007;104(20):8455-8460.

40. Hyman JM, Firestone AJ, Heine VM, et al. Small-molecule inhibitors reveal multiple strategies for Hedgehog pathway blockade. Proc Natl Acad Sci U S A. 2009;106(33):14132-14137.

41. Stanton BZ, Peng LF, Maloof N, et al. A small molecule that binds Hedgehog and blocks its signaling in human cells. Nat Chem Biol. 2009;5(3):154-156.

42. Kim DJ, Kim J, Spaunhurst K, et al. Open-label, exploratory phase II trial of oral itraconazole for the treatment of basal cell carcinoma. J Clin Oncol. 2014;32(8):745-751.

43. Ally MS, Ransohoff K, Sarin K, et al. Effects of combined treatment with arsenic trioxide and itraconazole in patients with refractory metastatic basal cell carcinoma. JAMA Dermatol. 2016;152(4):452-456.

44. Odomzo [package insert]. East Hanover, NJ: Novartis Pharmaceuticals Corporation; 2015.

45. Pan S, Wu X, Jiang J, et al. Discovery of NVP-LDE225, a potent and selective smoothened antagonist. ACS Med Chem Lett. 2010;1(3): $130-134$.

46. Rodon J, Tawbi HA, Thomas AL, et al. A phase I, multicenter, openlabel, first-in-human, dose-escalation study of the oral smoothened inhibitor Sonidegib (LDE225) in patients with advanced solid tumors. Clin Cancer Res. 2014;20(7):1900-1909.

47. Novartis Pharmaceuticals [webpage on the Internet]. Double-blind, Randomized, Vehicle-controlled Proof of Concept Study on the Efficacy, Safety, Local Tolerability, PK and Pharmacodynamics of Multiple Topical Administrations of LDE225 on Sporadic Superficial and Nodular Skin Basal Cell Carcinomas; 2011. ClinicalTrials.gov [Internet]. Available from: https://clinicaltrials.gov/ct2/show/record/ NCT01033019?term=LDE225\&rank=24. Accessed January 24, 2016.
48. Tang T, Tang JY, Li D, et al. Targeting superficial or nodular Basal cell carcinoma with topically formulated small molecule inhibitor of smoothened. Clin Cancer Res. 2011;17(10):3378-3387.

49. Danial C, Sarin KY, Oro AE, Chang AL. An investigator-initiated open-label trial of sonidegib in advanced basal cell carcinoma patients resistant to vismodegib. Clin Cancer Res. 2016;22(6):1325-1329.

50. Buonamici S, Williams J, Morrissey M, et al. Interfering with resistance to smoothened antagonists by inhibition of the PI3K pathway in medulloblastoma. Sci Transl Med. 2010;2(51):51ra70.

51. LoRusso PM, Rudin CM, Reddy JC, et al. Phase I trial of hedgehog pathway inhibitor vismodegib (GDC-0449) in patients with refractory, locally advanced or metastatic solid tumors. Clin Cancer Res. 2011;17(8):2502-2511.

52. Von Hoff DD, LoRusso PM, Rudin CM, et al. Inhibition of the hedgehog pathway in advanced basal-cell carcinoma. N Engl J Med. 2009; 361(12):1164-1172.

53. Eisenhauer EA, Therasse P, Bogaerts J, et al. New response evaluation criteria in solid tumours: revised RECIST guideline (version 1.1). Eur J Cancer. 2009;45(2):228-247.

54. Dummer R, Guminski A, Gutzmer R, et al. The 12-month analysis from Basal cell carcinoma outcomes with LDE225 treatment (BOLT): a phase II, randomized, double-blind study of sonidegib in patients with advanced basal cell carcinoma. J Am Acad Dermatol. 2016;75(1):e5-e125.

55. Migden MR, Guminski A, Gutzmer, et al. Treatment with two different doses of sonidegib in patients with locally advanced or metastatic basal cell carcinoma (BOLT): a multicentre, randomised, double-blind phase 2 trial. Lancet Oncol. 2015; 16(6):716-728.
OncoTargets and Therapy

\section{Publish your work in this journal}

OncoTargets and Therapy is an international, peer-reviewed, open access journal focusing on the pathological basis of all cancers, potential targets for therapy and treatment protocols employed to improve the management of cancer patients. The journal also focuses on the impact of management programs and new therapeutic agents and protocols on

\section{Dovepress}

patient perspectives such as quality of life, adherence and satisfaction The manuscript management system is completely online and includes a very quick and fair peer-review system, which is all easy to use. Visit http://www.dovepress.com/testimonials.php to read real quotes from published authors. 